\title{
Experimental characterization of the out-of-plane performance of regular stone masonry walls, including test setups and axial load influence
}

\author{
Tiago Miguel Ferreira ${ }^{1} \cdot$ Alexandre A. Costa $^{2}$. \\ António Arêde ${ }^{3} \cdot$ Ana Gomes $^{3} \cdot$ Aníbal Costa ${ }^{1}$
}

Received: 29 November 2014/Accepted: 3 March 2015/Published online: 13 March 2015

(C) Springer Science+Business Media Dordrecht 2015

\begin{abstract}
Stone masonry is one of the oldest and most worldwide used building techniques. Nevertheless, the structural response of masonry structures is complex and the effective knowledge about their mechanical behaviour is still limited. This fact is particularly notorious when dealing with the description of their out-of-plane behaviour under horizontal loadings, as is the case of the earthquake action. In this context, this paper describes an experimental program, conducted in laboratory environment, aiming at characterizing the out-of-plane behaviour of traditional unreinforced stone masonry walls. In the scope of this campaign, six full-scale sacco stone masonry specimens were fully characterised regarding their most important mechanic, geometric and dynamic features and were tested resorting to two different loading techniques under three distinct vertical pre-compression states; three of the specimens were subjected to an out-of-plane surface load by means of a system of airbags and the remaining were subjected to an out-of-plane horizontal line-load at the top. From the experiments it was possible to observe that both test setups were able to globally mobilize the out-of-plane response of the walls, which
\end{abstract}

Tiago Miguel Ferreira

tmferreira@ua.pt

Alexandre A. Costa

alc@isep.ipp.pt

António Arêde

aarede@fe.up.pt

Ana Gomes

anazgomes@fe.up.pt

Aníbal Costa

agc@ua.pt

1 Department of Civil Engineering, University of Aveiro, Campus Universitário de Santiago, 3810-193 Aveiro, Portugal

2 Department of Civil Engineering, School of Engineering, Polytechnic of Porto, Rua Dr. António Bernardino de Almeida, 431, 4200-072 Porto, Portugal

3 Faculty of Engineering, University of Porto, Rua Dr. Roberto Frias, s/n, 4200-465 Porto, Portugal 
presented substantial displacement capacity, with ratios of ultimate displacement to the wall thickness ranging between 26 and $45 \%$, as well as good energy dissipation capacity. Finally, very interesting results were also obtained from a simple analytical model used herein to compute a set of experimental-based ratios, namely between the maximum stability displacement and the wall thickness for which a mean value of about $60 \%$ was found.

Keywords Out-of-plane - Seismic behaviour - Stone masonry · Airbag · Line-load · Experimental testing

\section{Introduction}

Stone masonry is one of the oldest and most worldwide building techniques. Despite the remarkable longevity of many of the buildings erected with such technique, it is a fact that the great majority of this built heritage lacks of adequate seismic resistance, requiring therefore urgent retrofitting interventions in order to both reduce their seismic vulnerability and to cope with the increased requirements of recent European code standards (Ferreira 2015). However, if it is true that it can be considered as the simplest type of structural system concerning its assemblage, it is undeniable that, at the same time, it is one of the most complex construction materials in terms of mechanical properties and performance assessment. In addition, the behaviour of such structures under seismic excitation is clearly poor, calling into question both the preservation of a valuable heritage that should be protected and safeguarded and the security of people and goods.

\subsection{Seismic performance of stone masonry structures}

As pointed out by Costa (2012), structural reasons for the bad behaviour of masonry constructions during earthquakes are mainly due to its heterogeneity, anisotropic behaviour, negligible tensile strength and poor shear behaviour, which are further aggravated with the decreasing quality of masonry material and its assemblage. The out-of-plane damage or collapse mechanism is a widespread seismic failure mode in existing unreinforced masonry buildings, where insufficient or even no connection at floor levels is observed (Ferreira et al. 2014). Moreover, as traditional constructions on unreinforced masonry buildings possesses flexible diaphragms, it is not possible to take into account the contribution of returning walls to the seismic resistance and, for this reason, exterior masonry walls may behave independently on a cantilever mode, even for low seismic intensities. As a matter of fact, the out-of-plane collapse of unreinforced masonry walls
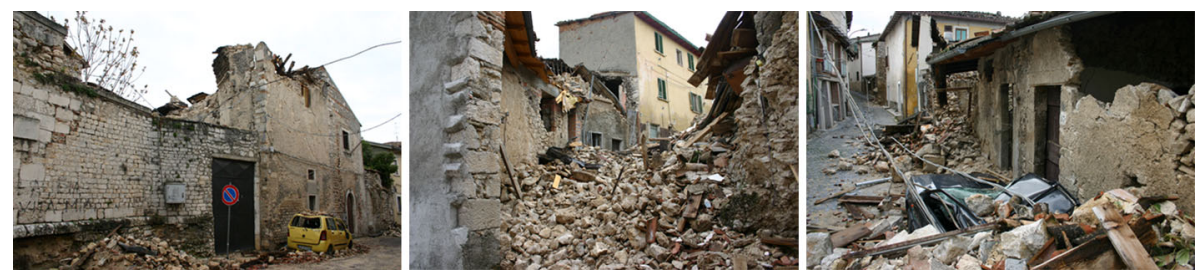

Fig. 1 Unreinforced stone masonry buildings damaged after the 2009 L'Aquila earthquake 
tends to occur at lower intensities than those required to produce collapse or heavy damage for in-plane response. Such fact, well known in the earthquake engineering community, has been convincingly demonstrated in recent earthquakes damage surveys in Italy (Decanini et al. 2004; Augenti and Parisi 2010; D’Ayala and Paganoni 2011), Spain (Romão et al. 2013), Turkey (Bayraktar et al. 2007a; b; Sayın et al. 2013, 2014) or in Pakistan (Maqsood and Schwarz 2010). Figure 1 depicts some examples of damage on traditional unreinforced stone masonry buildings, recorded after the magnitude 6.3 earthquake that struck L'Aquila city centre (central Italy) on the 6th of April 2009.

Concerning multi storey buildings and, despite the main post-earthquake observations shows that the out-of-plane collapse occurs mainly at the upper levels (due to dynamic amplification of the seismic action), it is also important to study the behaviour of a complete masonry wall. On insufficiently restrained very deformable masonry walls, the cantilever behaviour of the complete façade may occur, as included in the failure mechanisms presented by D'Ayala and Speranza (2003). For this reason, this work includes the study of lower level masonry walls of multi-storey masonry buildings to provide all the required data to deeply characterize the out-of-plane behaviour of unreinforced stone masonry walls.

\subsection{Scope and motivation}

The interest on such characterization has been increasing in recent years, namely with the development of some experimental works either in laboratory environment or in field. Among the various examples that could be cited here, a highlight for the recent experimental laboratory campaign presented by Restrepo-Vélez et al. (2014) and Vaculik et al. (2014), wherein a series of static 1:5 scale tests were performed on stone masonry walls with the aim of verifying existing analytical expressions for the computation of their horizontal resistance, and for the late in situ work of Costa et al. (2012b) in which a traditional two-storey masonry building was tested by means of the application of quasi-static loads at the building top level in the out-of-plane direction. Some further examples of relevant works were recently published in this field namely by Costa et al. (2013a, b), D'Ayala and Shi (2011) and Griffith et al. (2007). Nevertheless, the effective knowledge about the out-of-plane behaviour of masonry walls under earthquake action is still limited and the currently available experimental techniques are not completely stabilized and validated. In addition, a significant part of the available experimental data was obtained from investigations on reduced scale specimens, which may strongly influence some particular issues of the seismic resistance of real elements, or through testing schemes wherein the reproduction of existing materials or real in situ conditions are, at least, questionable.

Bearing in mind the above referred limitations, the work presented in this paper focuses on an experimental campaign carried out in laboratory environment in order to study the out-of-plane behaviour of stone masonry walls. The tests took place at Laboratory of Earthquake and Structural Engineering (LESE) of the Faculty of Engineering of the University of Porto, Portugal, and involved the construction of six full-scale unreinforced stone masonry walls, similar in terms of geometry and material characteristics, and their subsequent out-of-plane tests through the application of two different quasi-static loading schemes. The first loading scheme consisted of the application of a surface load resorting to a system of nylon airbags, while the second one consisted of the application of a horizontal line-load through a hydraulic actuator placed at the top of the masonry specimen. It is worth noting that these two loading schemes fall in the same research line of previous experimental works presented by this research team (e.g. Costa et al. (2012a, b) 
and Ferreira et al. (2012)). Note that the choice for using two different loading schemes in the experimental campaign reported herein has two main purposes: on one hand, the discussion of the results on the basis of the direct comparison between both setups, and on the other hand, the validation of these two schemes for in situ testing of stone masonry walls. Furthermore, taking into account past laboratory campaigns presented in the literature, this work presents some worth noting features such as the fact that the stone masonry specimens used were constructed by professional masons with stone material collected from real masonry structures and with mortars manufactured according to the traditional procedures. In addition, the analysis of the out-of-plane performance of the specimens was preceded by a thorough characterization of their morphological, mechanic and material properties.

\section{Characterisation of the masonry specimens}

De Felice (2011) highlighted that the out-of-plane behaviour of irregular stone masonry walls is strongly influenced, not only by the mechanical characteristics of the elements which compose the wall (stone units and infill material), but also by their geometrical characteristics and by the arrangement and fabric of the wall's section. Contrary to the Roman cementa (Luigli 1957) wherein the monolithic behaviour of the wall is ensured by the cohesion of the mortar, in sacco stone masonry the mortar is usually not strong enough to provide sufficient bond to the wall assemblage. In fact, for this type of masonry, mortar is used almost exclusively to fill the voids between stone units. For most of the masonry walls, and particularly for multi-leaf masonry walls, a proper transversal bond should be provided by good workmanship in order to improve the monolithic behaviour of the wall. Besides the cited work of De Felice (2011), several works aiming to study the influence of the transverse bonding on the out-of-plane strength capacity of masonry walls have been presented in the last decades. Guiffrè $(1990,1996)$ was one of the authors that addressed this topic. In his socalled opus quadratum model, the author carried out a series of numerical and experimental studies where the influence of the number of header blocks on the out-of-plane strength capacity was clearly highlighted. Such influence was demonstrated by an almost linear decrease of the ratio between the real and the supposed monolithic wall, $\lambda_{0}$, when increasing the $s / t$ ratio between the vertical distance among headers (also known as through stones), $s$, and the thickness of the wall, $t$. However, as later remarked by Trovalusci and Baggio (2003), because the work resorted only squad stones, its application is somewhat limited due to the variability and complexity of stone masonry sections that could never be completely covered. Additionally, irregularities of stone units may induce more complex features of the overall behaviour. Hence, taking into account the importance of all the above mentioned parameters on the characterisation of the out-of-plane behaviour of rubble stone masonry walls, a thorough characterisation of the six stone masonry walls used in this experimental work, will be presented in the following sections taking into account their construction process as well as type of stone, geometry and dynamic features.

\subsection{Walls construction and geometric characterization}

As noted above, the masonry test specimens were constructed by professional masons under controlled laboratory conditions. The six masonry walls are $1.30 \mathrm{~m}$ long, $0.65 \mathrm{~m}$ thick and $2.50 \mathrm{~m}$ high, leading to a slenderness ratio $h / t$ of 3.85 and a volume of $2.11 \mathrm{~m}^{3}$ 
each. Idealised and constructed to be representative of one of the traditional Mediterranean masonry construction typologies, the specimens are composed of non-regular roughly squared granite blocks and non-cohesive infill material. Figure 2 presents the construction stage and the final aspect of some of the stone masonry walls.

Assuming that the out-of-plane seismic capacity of masonry walls is highly dependent on the morphology of the wall section and stone laying technique, the following features were taken into account: percentage of headers, stone shape and dressing, stone dimensions and regularity of the mortar courses. Among them, particular care was taken in the survey to classify the stones, according to their arrangement in the wall, as stretchers, when their length lies longitudinally in the wall, or as headers, when their length is perpendicular to the faces.

As already discussed, the presence and the number of headers clearly affect the transversal bond of the wall. According to Swain (1927), "to bind the wall transversally, there should be a considerable number of headers extending from the front to the back of thin walls and from the outside to the inside of thick walls". In consequence of this, the author suggests a percentage of headers not less than $20 \%$ of the area of the face. Thus, in order to study the sectional characteristics of the masonry walls, each one of the six specimens was discretized and reproduced in CAD by means of polygonal blocks which depict the shape, the size and the arrangement of the stone elements of the walls' sections. The result of this survey is shown in Fig. 3. In order to highlight its presence and location, the headers are presented with a hatched patterns.

Furthermore, Table 1 summarizes the number of headers present in each one of the walls' sections as well as the vertical distance among them and the ratio between the total area of headers and the area of the wall's face.

From the analysis of the values presented in Table 1, it is worth highlighting that two of the six masonry walls (wall 2 and 3 ) present a ratio of the area of the headers to the area of the cross-section lower than $20 \%$ which is the minimum value recommended by (Swain 1927).

\subsection{Materials characterization}

As introduced in the previous section, the masonry walls are made of non-regular roughly squared granite blocks and a non-cohesive infill material (small stone fragments and soil type material binded with a traditional lime mortar). The granite blocks used were collected from old masonry constructions located in North Portugal and the mortars, composed of lime and clay (with 1:3 ratio), were formulated and prepared in laboratory following the traditional procedures.
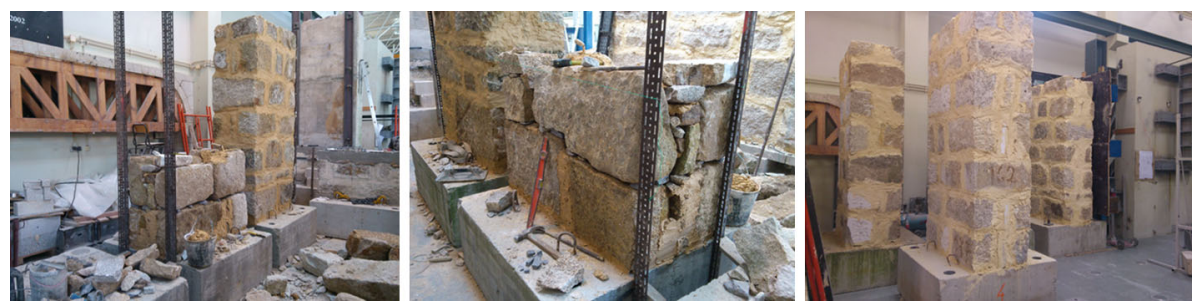

Fig. 2 Construction and preparation of the masonry walls 


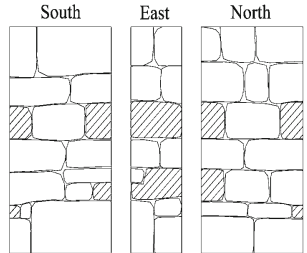

Wall 1

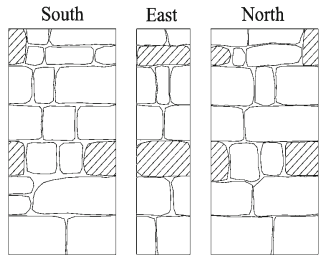

Wall 4
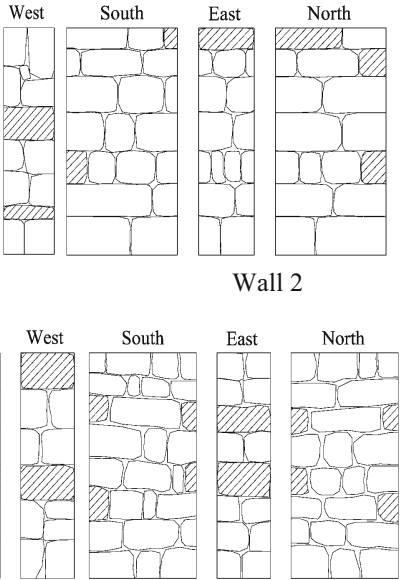

Wall 5
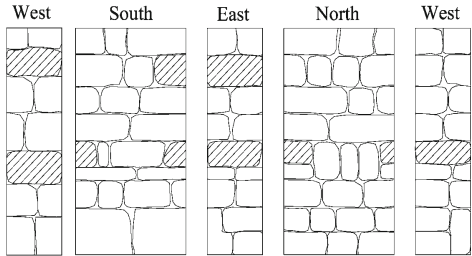

Wall 3
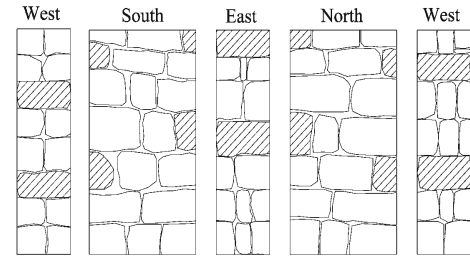

Wall 6

Fig. 3 Geometrical survey of the six masonry walls

Table 1 Characterisation of the cross-sections taking into account the presence of headers

\begin{tabular}{|c|c|c|c|c|c|c|c|c|c|c|}
\hline \multirow[t]{2}{*}{ Specimen } & \multicolumn{2}{|c|}{$\begin{array}{l}\text { Number of } \\
\text { headers }\end{array}$} & \multicolumn{2}{|c|}{$\begin{array}{l}\text { Distance among } \\
\text { headers }(\mathrm{m})\end{array}$} & \multicolumn{2}{|c|}{$\begin{array}{l}\text { Area of } \\
\text { headers }\left(\mathrm{m}^{2}\right)\end{array}$} & \multicolumn{2}{|c|}{$\begin{array}{l}\text { Percentage of } \\
\text { headers }(\%)\end{array}$} & \multicolumn{2}{|c|}{$\begin{array}{l}\text { Distance from } \\
\text { foundation to first } \\
\text { headers }(\mathrm{m})\end{array}$} \\
\hline & East & West & East & West & East & West & East & West & East & West \\
\hline Wall 1 & 2 & 2 & 0.34 & 0.74 & 0.45 & 0.32 & 28 & 20 & 0.60 & 0.39 \\
\hline Wall 2 & 1 & 2 & - & 0.82 & 0.15 & 0.43 & 9 & 27 & 2.25 & 0.78 \\
\hline Wall 3 & 2 & 1 & 0.60 & - & 0.50 & 0.28 & 31 & 18 & 0.97 & 1.00 \\
\hline Wall 4 & 2 & 2 & 0.84 & 0.84 & 0.39 & 0.51 & 25 & 32 & 0.86 & 0.87 \\
\hline Wall 5 & 2 & 2 & 0.44 & 0.85 & 0.46 & 0.45 & 29 & 28 & 0.91 & 0.63 \\
\hline Wall 6 & 2 & 2 & 0.70 & 0.71 & 0.45 & 0.38 & 28 & 24 & 1.10 & 0.72 \\
\hline
\end{tabular}

According to EN 14580 (2005), (2006) and ASTM C 496-71 (2001), seventeen stone samples (cylindrical with $100 \mathrm{~mm}$ diameter and $200 \mathrm{~mm}$ high) were tested under air dry laboratory environment in order to evaluate their compressive strength, $f_{c b}$, Elastic Modulus, $E_{c b}$, and tensile strength, $f_{t b}$. It is important to note that these mortars are also used on the scope of other experimental work carried out in LESE and that, for this reason, the following results are also reported in Almeida (2013). In terms of average values (and coefficient of variation, $\mathrm{CoV})$, the following values were obtained: $43.83 \mathrm{MPa}(15.96 \%)$ for the compressive strength, $13.85 \mathrm{GPa}(24.49 \%)$ for the Elastic Modulus and 3.37 MPa $(13.57 \%)$ for the tensile strength. It is worth noting that these results are in the range of those reported in similar studies [see (Augenti et al. 2012; Vasconcelos 2005)], though it is very likely that the differences registered in the mechanical characteristics of the stone blocks, evidenced by the obtained coefficients of variation, are sufficient to influence the global strength of the masonry walls (Almeida et al. 2012).

In order to characterise the mechanical properties of the mortars, compressive and flexural strength tests were performed on two sets of six prismatic mortar samples (with $160 \times 40 \times 40 \mathrm{~mm}$ ) with a curing period of 90 days (see Fig. 4). The testing procedure 


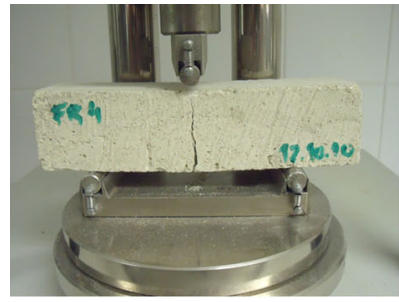

(a)

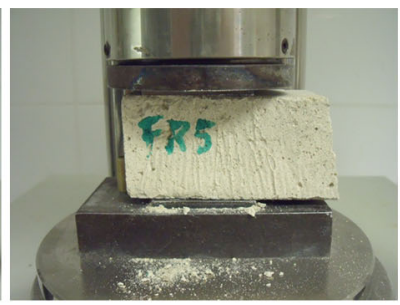

(b)

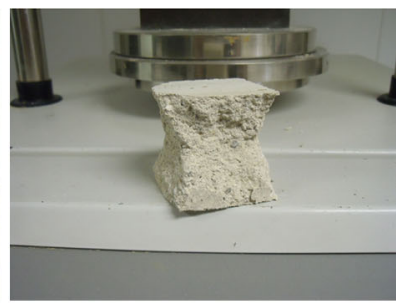

(c)

Fig. 4 Mortar specimen: a flexural strength test; $\mathbf{b}$ compression strength test; $\mathbf{c}$ final aspect of the specimen after the compression strength test

adopted is in accordance with the standard (EN 1015-11 1999) and, as in the previous case, the results herein presented for mortars are also already reported in Costa et al. (2013c).

The compressive strength and flexural strength values were similar in both sets of samples, giving average values of $1.28 \mathrm{MPa}(2.66 \%)$ and $0.53 \mathrm{MPa}(11.83 \%)$, respectively. Once again, it should be noted that such values are consistent with the expected values for this type of mortar [see for example (Almeida 2013; Augenti et al. 2012; Magalhães and Veiga 2009)].

\subsection{Modal identification}

In order to determine the natural frequencies and the modal response of each one of the six masonry walls, a series of vibration tests was performed before the beginning of the tests. Among other interesting outputs, the modal analysis of the specimens led to different conclusions regarding some of their main mechanical properties in a non-tested state (for example the Elastic Modulus). The goal of the following measurements consisted on identifying the first two natural frequencies and corresponding mode shapes of the masonry specimens, with the purpose of analytically estimating the Elastic Modulus value. This approach may be particularly important for practical engineers when dealing with existing masonry buildings.

The measurements of the dynamic behaviour of the masonry walls were performed using LabVIEW SignalExpress software (National Instruments 2010) to log the data acquired from five unidirectional accelerometers (see Fig. 5) in time frames with approximately $3 \mathrm{~min}$, excited with ambient noise vibration. The modal analysis of the specimens were subsequently performed by means of the peak picking and frequency domain decomposition (FDD) techniques, implemented in the ARTeMIS Extractor software (Structural Vibration Solution 2012), from which the first two natural frequencies, vibration mode shapes and damping ratios were identified. Figure 5 shows the location of the accelerometers and the mesh used to visualize the mode shapes.

Due to laboratory limitations, the measurements were performed at a time when the setups for the out-of-plane tests were already assembled. As a result, the dynamic response of the six masonry specimens was registered under two distinct support conditions, namely cantilever (walls 1-3, Fig. 6) and fixed-pinned (walls 4-6, Fig. 7); which led to the consideration of two different structural schemes on the analytical estimation of the Elastic Modulus of the walls. The equivalent structural schemes used for the case of the cantilever and fixed-pinned wall as well as the first two vibration mode shapes are depicted in Figs. $6 \mathrm{~b}$ and $7 \mathrm{~b}$, respectively. 

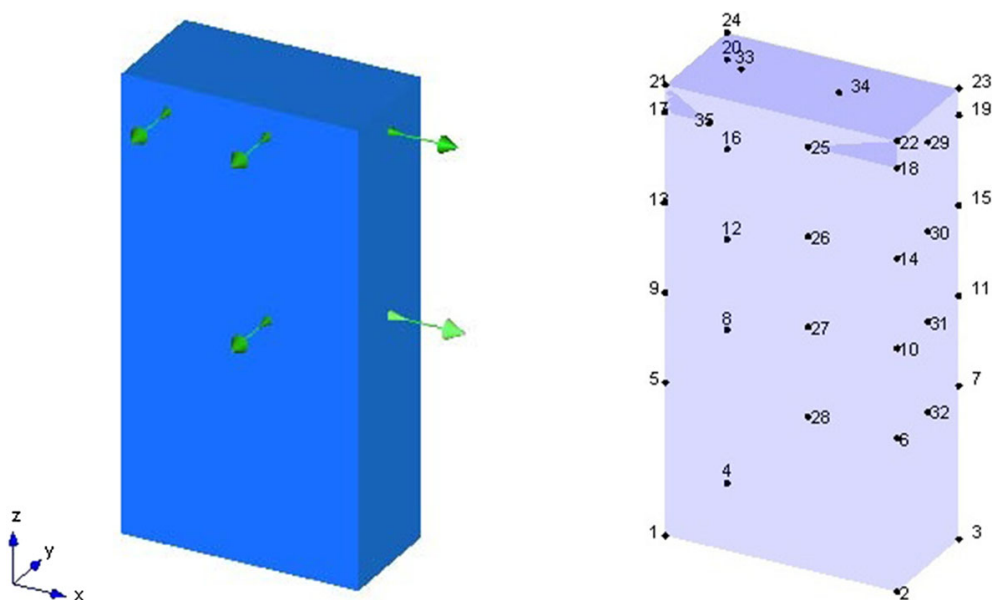

Fig. 5 Location of the five accelerometers and mesh used in modal identification

As an example, Fig. 8 shows the power spectral density obtained from the measurement performed in wall 1 .

As aforementioned, the data obtained from the modal identification was therefore used in the estimation of the Elastic Modulus of the walls. According to structural dynamics the theory, the Elastic Modulus of a structural system can be estimated based on their fundamental frequencies. As given in Clough and Penzien (1975), the first fundamental angular frequencies of a cantilever beam and a fixed-pinned beam can be determined using Eqs. (1) and (2), respectively:

$$
\begin{gathered}
w_{c}=1.875^{2} \sqrt{E I / \bar{m} l^{4}} \\
w_{f p}=\pi^{2} \sqrt{E I / \bar{m} l^{4}}
\end{gathered}
$$

where $E$ is the Elastic Modulus, $I$ is the moment of inertia of the wall cross-section in the considered direction, $\bar{m}$ is the wall mass per unit length and $l$ stands for the total height of the wall. Table 2 presents the natural frequencies obtained with the monitoring scheme

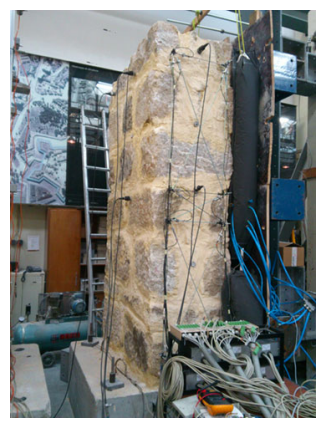

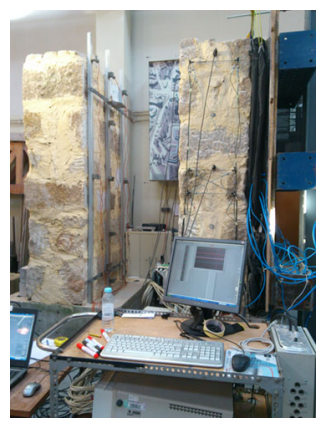

(a)

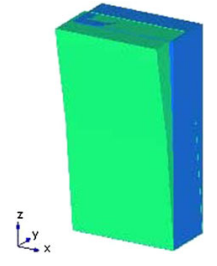

Transversal mode

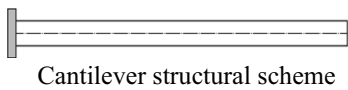

(b)

Fig. 6 Cantilever walls: a experimental apparatus; b first two vibration mode shapes and equivalent structural scheme 

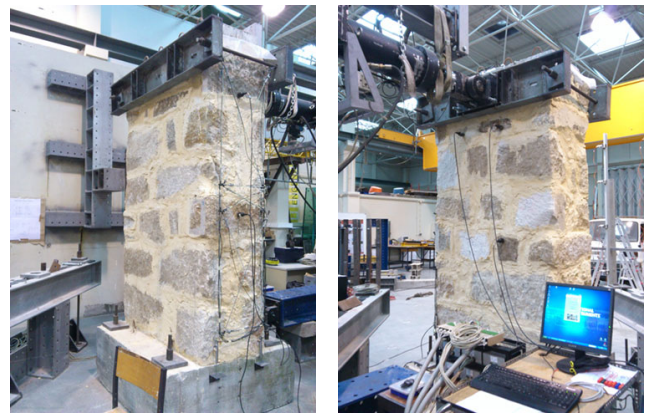

(a)

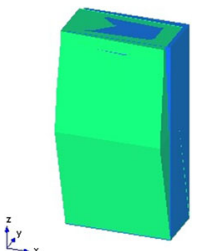

Transversal mode

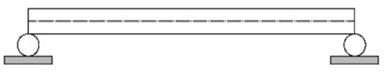

Pinned-pinned structural scheme

(b)

Fig. 7 Pinned-pinned walls: a experimental apparatus; b first two vibration mode shapes and equivalent structural scheme

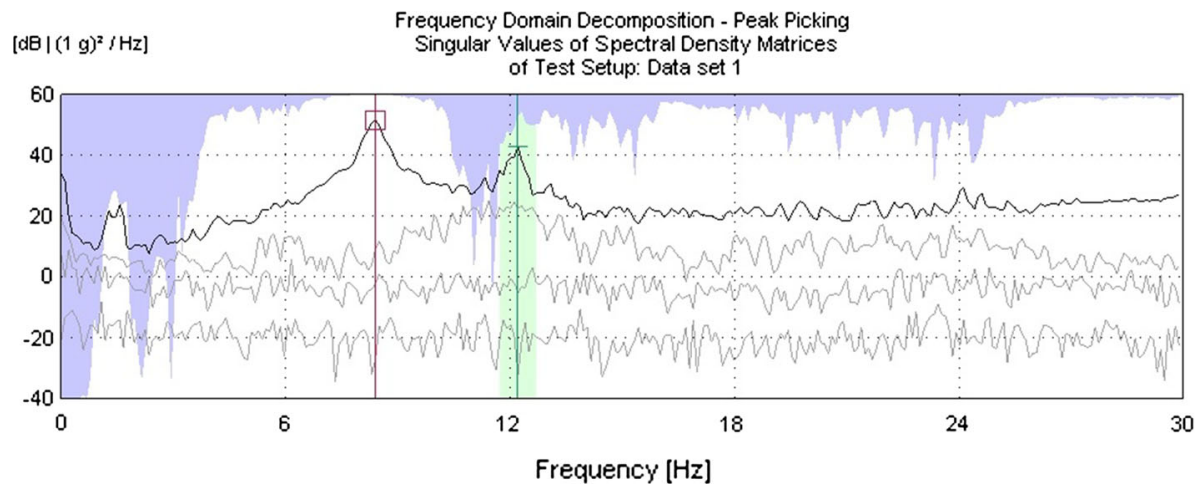

Fig. 8 Wall 1: identification of spectral peaks

presented in Fig. 5, as well as the values of the Elastic Modulus estimated using Eqs. (1) and (2), considering a unit weight, $\gamma$, of $21 \mathrm{kN} / \mathrm{m}^{3}$ (experimentally measured before the out-of-plane tests).

From the values obtained for the Elastic Modulus and taking into account the mass density of the walls, the values obtained are consistent with the masonry typology reported in the Italian code (Consiglio Superiore dei lavori Pubblici 2009) (Table C8A.2.1) as

Table 2 Fundamental frequencies and Elastic Modulus in the transversal direction (yy)

\begin{tabular}{llll}
\hline Specimen & Structural scheme & Fundamental frequency $(\mathrm{Hz})$ & Elastic Modulus $(\mathrm{GPa})$ \\
\hline Wall 1 & Cantilever & 8.39 & 0.53 \\
Wall 2 & & 7.42 & 0.42 \\
Wall 3 & & 7.25 & 0.40 \\
Wall 4 & \multirow{2}{*}{ Pinned-pinned } & 21.34 & 0.44 \\
Wall 5 & & 24.59 & 0.58 \\
Wall 6 & & 24.66 & 0.59 \\
& & Mean value & $0.49 \mathrm{GPa}$ \\
& & Coef. variation & $17.1 \%$ \\
\hline
\end{tabular}


"ashlar masonry with internal core", wherein the range of the main mechanical parameters for this masonry typology, i.e. compressive strength, shear strength, elastic modulus, shear modulus and mass density, can be consulted.

\section{Test programme and loading procedure}

As already introduced, this experimental campaign aimed at characterizing the out-ofplane behaviour of six full-scale masonry walls resorting to quasi-static loads applied by means of two different testing setups and under three distinct pre-compression states. The first test setup consisted of the application of a uniformly distributed surface load using a system of three nylon airbags (with $1600 \mathrm{~mm}$ height, $700 \mathrm{~mm}$ width and $350 \mathrm{~mm}$ thick), which reacts against a backing frame. The latter is connected to a reaction structure composed of a set of HEB steel beams, connected to the reaction wall of the laboratory with mechanical anchors (Figs. 6a and 9). The level of pressure inside the airbags and the top displacement of the specimen, used as control displacement during the tests, were continuously acquired through a data acquisition system. For easy interpretation, the three airbag tests were denominated respectively as OP PA1, OP PA2 and OP PA3 where the prefix OP stands for Out-of-plane and the suffix PA(i) refers to the setup used (PA for airbag testing) and the number of the test $(i=1-3)$.

The second test setup consisted on the application of a horizontal line-load by means of a displacement-controlled hydraulic actuator. In order to avoid an eventual torsional response of the specimen, the actuator was horizontally centred at the top of the back surface of the masonry wall. The actuator reaction is provided by a stiff steel structure, anchored to the test slab of the laboratory, Fig. 9b. In accordance with what has been said for the airbag tests, the three line-load tests were denominated as OP PF1, OP PF2 and OP PF3 wherein $\mathrm{PF}$ refers to the concentrated force test setup.

Concerning the foundations of the specimens, it is worth mentioning that these traditional masonry constructions usually do not include any special foundation element, being simply settled on soil with some layered bottom stones right below the ground level. This situation is naturally more common in low-rise buildings, which usually do not need very deep and large foundations. Consequently, aiming at full control the boundary condition of the experiments, all the masonry walls were tested on

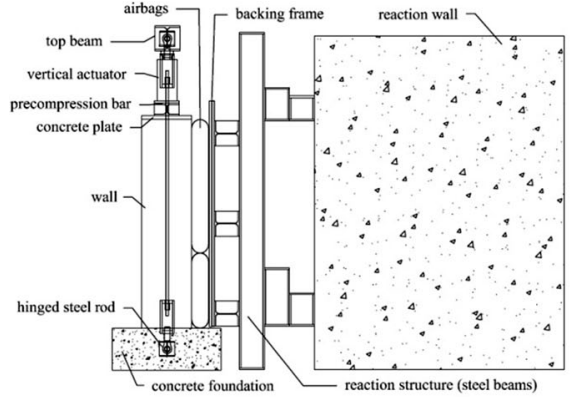

(a)

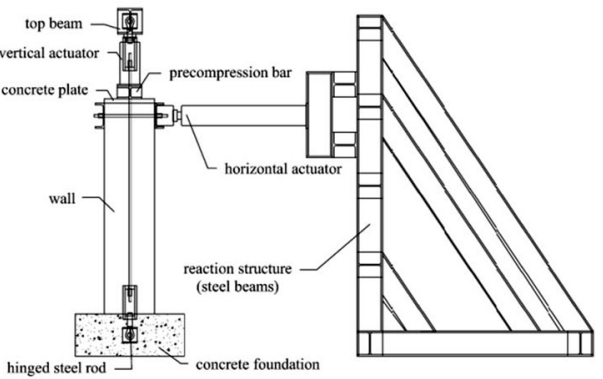

(b)

Fig. 9 Lateral view of the test setups with the application of a vertical pre-compression force. a Airbag testing, b Line-load testing 
a cantilever structural scheme, settled on a concrete footing, independently from the pre-compression level and the test setup. Note that, even in the most unfavourable case, i.e. with no axial compression force, the friction between the concrete footing and the first layer of granitic stones is sufficient to guaranty that no sliding will occur at the base of the wall. This issue was also monitored during the experiments with a displacement transducer between the bottom of the wall and the concrete footing, and no sliding occurred.

In order to apply the vertical load, a hydraulic actuator was installed at the top of the masonry wall, reacting against a steel frame connected to the foundation through hinged steel rods in which load cells were used to measure the imposed force. Figure 9 presents the apparatus of both test setups with the application of a vertical pre-compression force.

The pre-compression force was chosen to reproduce a realistic vertical load according to the specifications presented in Table 3. Such values were determined considering a unit weight for masonry $\gamma=21 \mathrm{kN} / \mathrm{m}^{3}$ and two additional loads of 1.2 and $1.5 \mathrm{kN} / \mathrm{m}^{2}$, distributed with a tributary length of $2.0 \mathrm{~m}$ in order to simulate respectively the roof and floors weight of a traditional Mediterranean house.

As the vertical hydraulic actuator used is not force-controlled and consequently a significant variation of vertical compression was observed during the experimental tests, as depicted in the time history of vertical loading shown in Fig. 10a. This non-negligible load variation was due to the absence of oil volume correction inside the hydraulic actuator to compensate the uplifting and the vertical deformation of the specimen. The peaks in the plots of Fig. 10a refer to the wall uplift, whereas the clear global decreasing trend is due to the average compressive deformation for which no correction was provided on the total axial force. It is important to note that this variation on the vertical force was taken into account in the treatment of the experimental data, through the consideration of a variation factor, $\Delta_{N}$, which can be obtained for each rotation instant by means of Eq. (3):

$$
\Delta_{N}(\theta)=N \cdot(1-\cos \theta)
$$

where $N$ represents the applied axial pre-compression force and $\theta$ is the wall rotation at each instant of time, experimentally measured by means of an inclinometer placed on the top of the wall. Evaluated the variation of the axial pre-compression force, the final corrected force, $F$, is given by Eq. (4):

Table 3 Overburden conditions used in the tests

\begin{tabular}{|c|c|c|c|c|c|}
\hline \multirow[t]{2}{*}{ Specimen } & \multirow[t]{2}{*}{ Test } & \multicolumn{3}{|c|}{ Overburden conditions } & \multirow[t]{2}{*}{ Corresponding wall in real buildings } \\
\hline & & $\mathrm{N}(\mathrm{kN})$ & $\begin{array}{l}\sigma_{\text {base }} \\
(\mathrm{kPa})\end{array}$ & $\Psi^{\mathrm{a}}$ & \\
\hline Wall 1 & OP PA1 & \multirow[t]{2}{*}{0} & \multirow[t]{2}{*}{52.5} & \multirow[t]{2}{*}{0} & \multirow[t]{2}{*}{ Single-storey load-bearing wall } \\
\hline Wall 4 & OP PF1 & & & & \\
\hline Wall 2 & OP PA2 & \multirow[t]{2}{*}{52} & \multirow[t]{2}{*}{113.3} & \multirow[t]{2}{*}{1.17} & \multirow{2}{*}{$\begin{array}{l}\text { Load-bearing ground storey wall of a 2-storey } \\
\text { building }\end{array}$} \\
\hline Wall 5 & OP PF3 & & & & \\
\hline Wall 3 & OP PA3 & \multirow[t]{2}{*}{140} & \multirow[t]{2}{*}{227.5} & \multirow[t]{2}{*}{3.15} & \multirow{2}{*}{$\begin{array}{l}\text { Load-bearing ground storey wall of a 4-storey } \\
\text { building }\end{array}$} \\
\hline Wall 6 & OP PF3 & & & & \\
\hline
\end{tabular}

\footnotetext{
a Overburden ratio: ratio of axial load to wall weight
} 


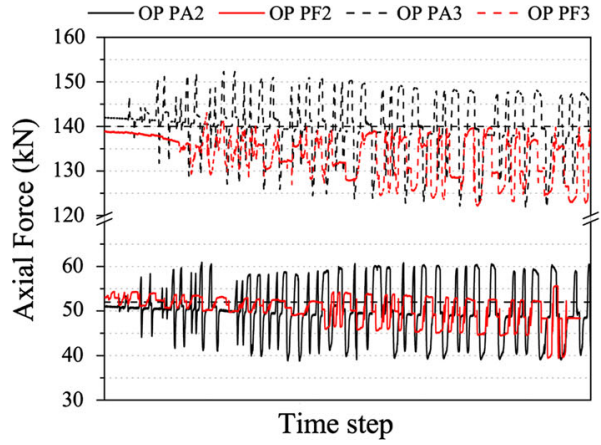

(a)

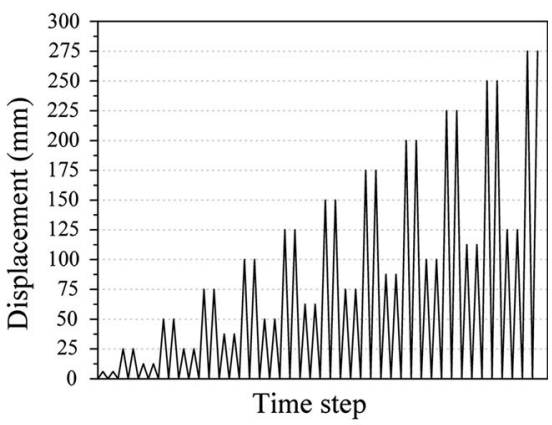

(b)

Fig. 10 Loading histories. a Vertical pre-compression force. b Horizontal top displacement protocol

$$
F(\theta)=\left(F_{m}-N \sin \theta\right)-\frac{\Delta_{N} \times t}{2 h}
$$

where $F_{m}$ is the measured force, i.e. the value obtained directly from the data acquisition system, and $t$ and $h$ are respectively the thickness and the height of the wall.

As presented in Fig. 10b, the horizontal loading history used in both test setups consisted on performing two complete displacement controlled cycles, alternated by two smaller cycles with half the amplitude of the previous, before increasing the amplitude by $25 \mathrm{~mm}$. This load history was defined so as to make it possible to observe the hysteretic behaviour of the masonry walls caused by the unloading/reloading in the same direction. In this sense, two small initial cycles of $6 \mathrm{~mm}$ were used to analyse the linear elastic behaviour, while two cycles of $25 \mathrm{~mm}$ peak intended to reach the maximum strength on the wall without significant damage.

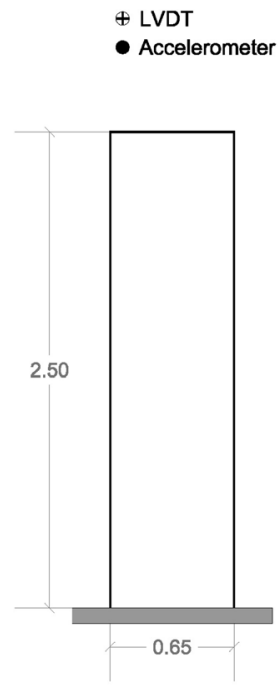

A-A
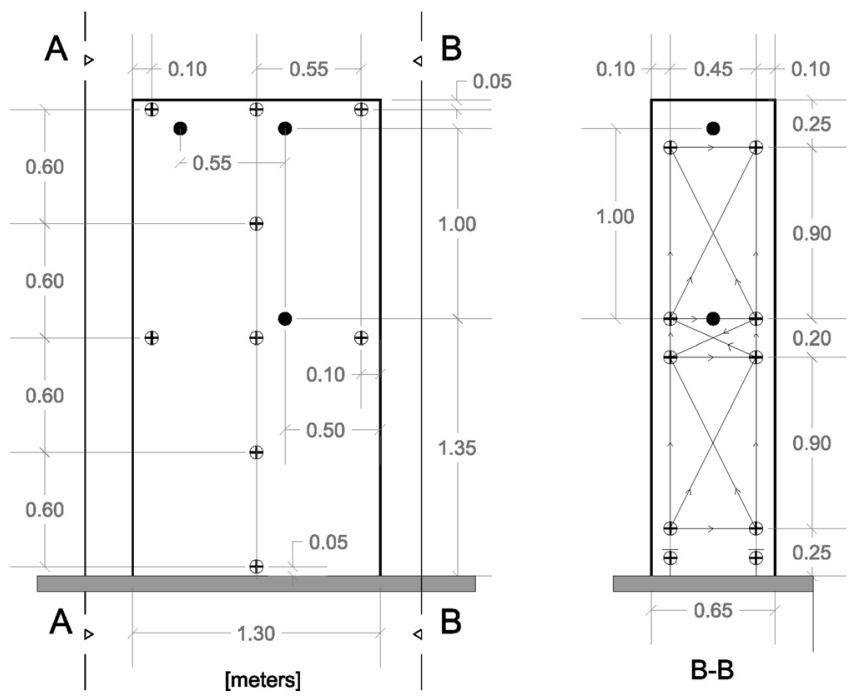

Fig. 11 Monitoring scheme 
In both test setups, the masonry walls' response was monitored with a set of 27 linear variable displacement transducers (LVDTs) positioned to measure the deflected wall profile, the global vertical deflections, the joint opening-closing between stone units and the out-of-plane movement, see Fig. 11. As also depicted in Fig. 11, five accelerometers were used to record the natural frequencies of the masonry specimen during the out-ofplane tests.

\section{Results and data interpretation}

\subsection{Experimental evidences}

The results obtained from the experiments are presented and discussed in the present section. However, before going into the discussion, it is important to highlight that the values of overturning moments presented were computed on the basis of the force resultants acting on the walls, which are schematically depicted in Fig. 12.

Thus, the experimental data obtained from the airbag tests and in the line-load tests are presented in Figs. 13 and 14, in the form of hysteretic curves and envelopes respectively. In order to compare directly the results obtained from each test setup, they are both plotted in the form of overturning moment versus rotation and also in terms of force versus relative rotation. It is worth stressing that, in the case of the airbag tests, the force values presented in the right axis of Fig. 13a correspond to the force resultant obtained from the surface pressure measured directly during the tests (Fig. 12). Moreover, these airbag test results were corrected using a correction factor that takes into account the effective pressure, correlated to the airbags insufflation. However, despite the importance of this aspect, its discussion is out of the scope of this paper, but further considerations can be found in Gomes et al. (2013). The key issues from the experimental tests are summarized and compared in Table 4.

As it is possible to observe from Fig. 13, for the same level of axial load, the results are rather consistent both in terms of elastic stiffness and maximum overturning moment; see Table 4 where $K_{\text {ini }}$ and $K_{\text {eff }}$ represents the initial and the effective stiffness of the wall, obtained respectively from 10 to 40 , and $70 \%$ of the maximum experimental overturning moment, $M_{\max }$. In addition, $M_{\min (\theta M u)}$ is the overturning moment corresponding to the minimum ultimate rotation attained (in this case $\theta_{M u(O P P F 1)}$ ) and $M_{u}$ is the overturning moment corresponding to the maximum experimental rotation (or displacement).

Fig. 12 Force resultants acting on the wall, including the horizontal component of the force exerted by the actuator and $\mathrm{P}-\Delta$ effects. a Airbag testing, b Line-load testing

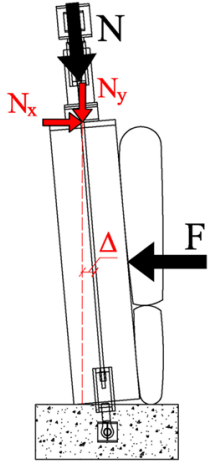

(a)

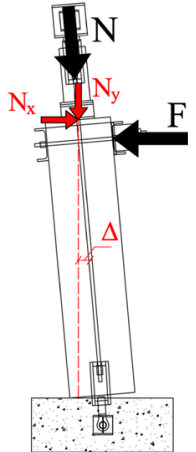

(b) 


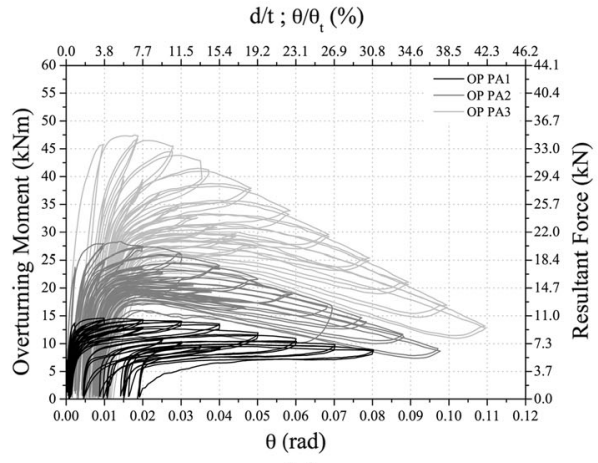

(a)

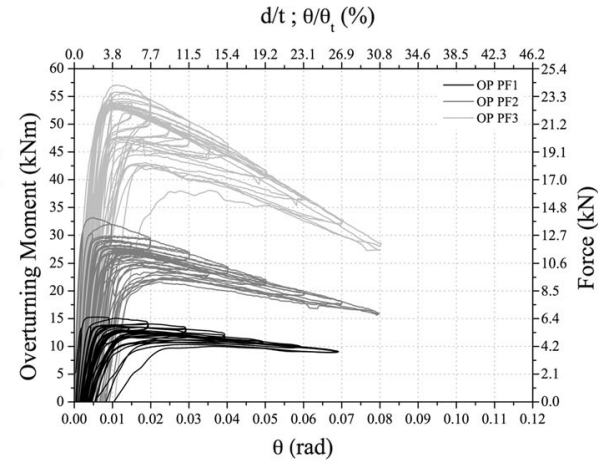

(b)

Fig. 13 Overturning moment versus rotation: hysteretic curves for airbag (a) and line-load tests (b)

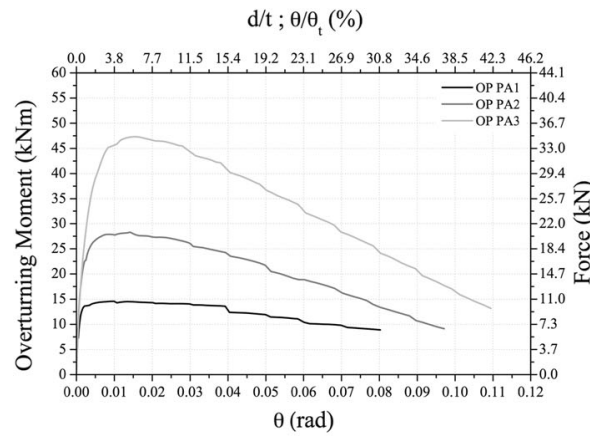

(a)

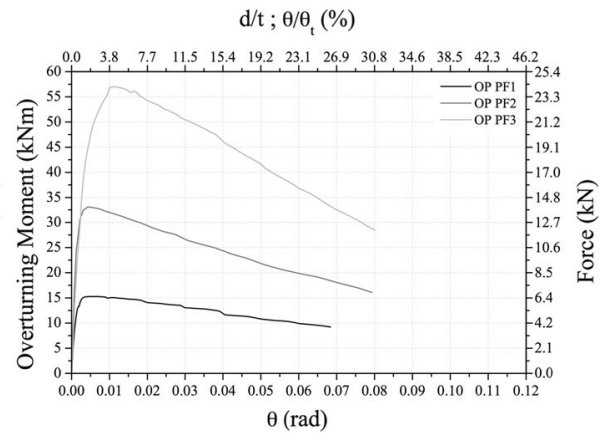

(b)

Fig. 14 Overturning moment versus rotation envelopes for airbag (a) and line-load tests (b)

Average values of initial stiffness, $K_{\text {ini }}$, of 3640,4015 and $4745 \mathrm{kN} / \mathrm{m}$ were obtained for the tests with axial load of $0 \mathrm{kN}$ (OP PA1 and OP PF1), $52 \mathrm{kN}$ (OP PA2 and OP PF2) and $140 \mathrm{kN}$ (OP PA2 and OP PF3), respectively. In general terms, the walls exhibited substantial displacement capacity with ratios of ultimate displacement to wall thickness, $d_{M u} / t$, ranging between 26 and $42 \%$. As also presented in Table 4, all the experiments were carried out until a strength decrease $\left(M_{u} / M_{\max }\right)$ of at least $40 \%$ was reached, because the out-of-plane behaviour of masonry walls may be seen as nonlinear elastic. It is worth mentioning that displacements were imposed until one of the following stopping criteria was satisfied: (1) strength degradation of $20 \%$ relative to the maximum measured strength exhibited (attained in all tests); or/and (2) the limit stability or safety conditions could be ensured.

The height wise horizontal displacement' profiles during the tests are presented in Fig. 15.

From the height wise horizontal displacement profiles, it is possible to see that the imposition of a concentrated load did not lead to damage concentration at the top of the wall during its outward movement. In fact, the walls subjected to the line-load scheme were found to be globally mobilized with this test setup. However, it is important to 


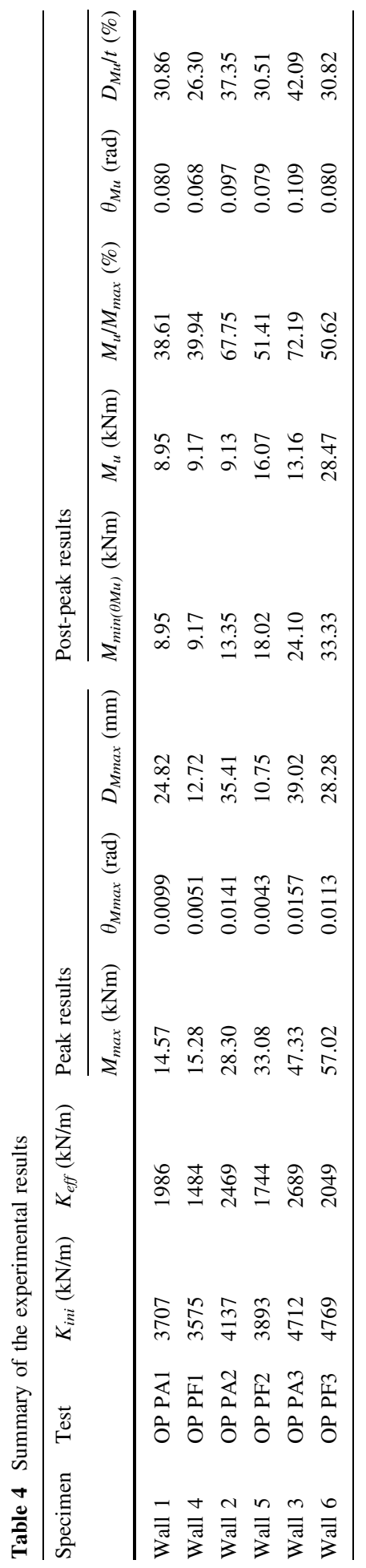


highlight that, due to the effective connection of the horizontal actuator to the wall, some more damage was observed when it was been pushed in the inward direction, particularly for higher displacements. This fact occurs because, contrary to what happens in the case of the airbags setup where, although the system is uncharged at the end of each loading cycle, the wall always exhibits some residual top displacement, in the case of the line load setup, the hydraulic actuator always forces the wall to return to its initial position $(\Delta=0)$, thus imposing damage in that direction. As shown in Fig. 15b, this issue is particularly evident for those cases where the level of axial compression is low, and only in the range of large displacements (OP PF1). In general terms, and as mentioned latter, this fact is due to a lower flexural resistance of the mortar bed joints for low levels of axial stress. In addition, some base slip effect is also notable in the base of the walls' horizontal displacement profiles.

Figure 16 presents the direct comparison between the height wise horizontal displacement profiles for three distinct displacement levels: $6 \mathrm{~mm}$ (corresponding to the initial load cycle), $100 \mathrm{~mm}$ (corresponding to the intermediate load cycle) and $175 / 200 \mathrm{~mm}$ (corresponding to the final load cycle).
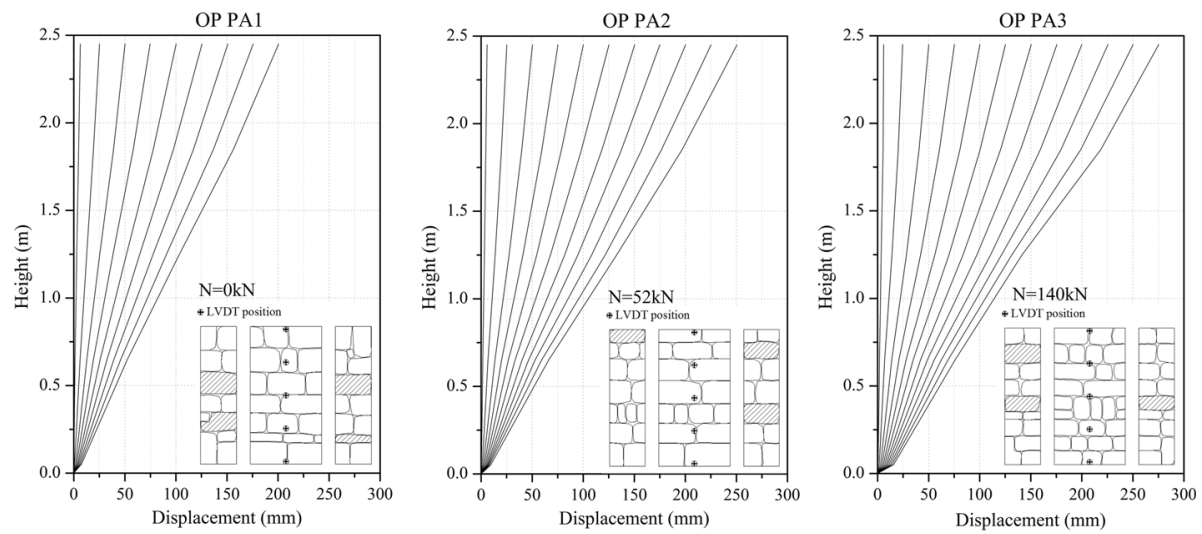

(a)
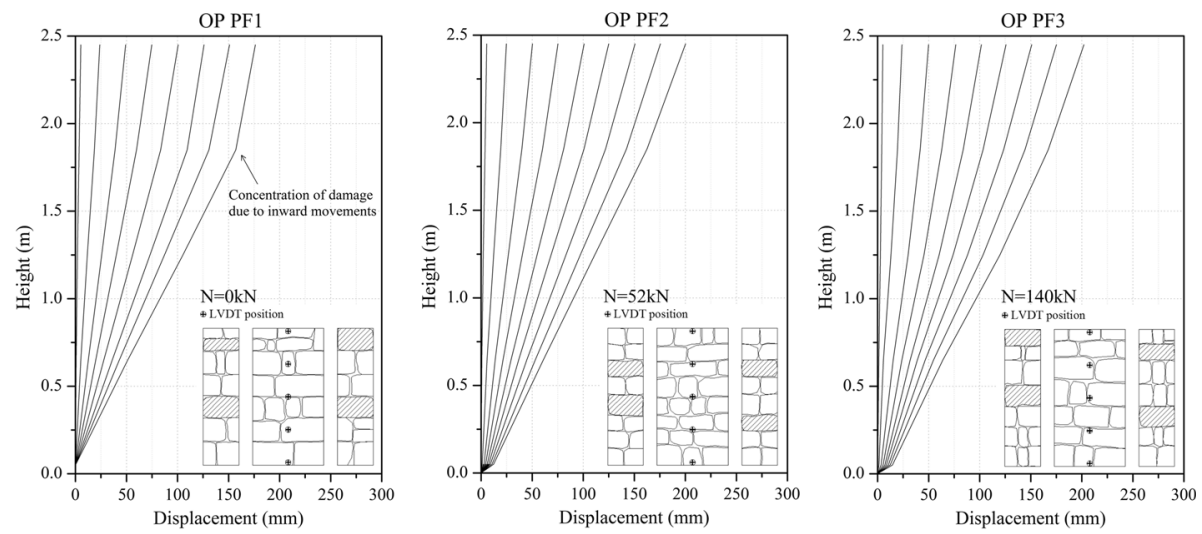

(b)

Fig. 15 Height wise horizontal displacement' profiles with position of the displacement transducers. a Airbag tests, b Line-load tests 

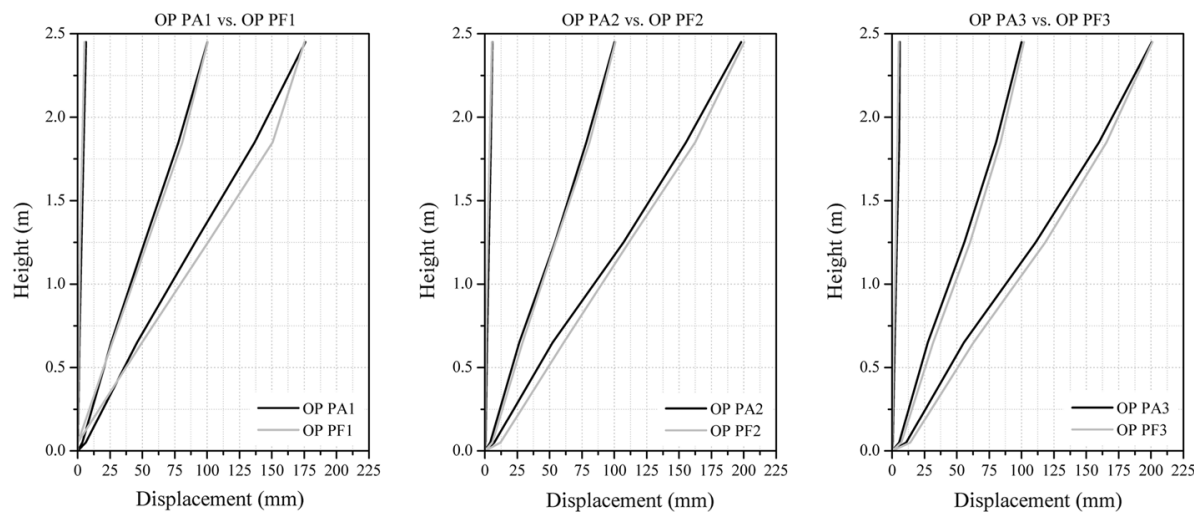

Fig. 16 Comparison between height wise horizontal displacement profiles obtained

\subsection{Influence of the vertical pre-compression on the peak and post-peak capacity}

In general, specimen comparisons showed that the higher the vertical pre-compression is applied, the larger displacement capacity is reached. Likewise, both the peak and post-peak overturning moment capacity of walls with vertical pre-compression outperformed walls without pre-compression (refer Table 4). Concerning the first increment of axial load (level 1 to level 2), there was an average increase of $106 \%$ in $M_{\max }$ and $73 \%$ in $M_{\min (\theta M u)}$, as a result of a $60.8 \mathrm{kPa}$ stress increase due to axial pre-compression (Table 3). Following the same trend, with the second axial pre-compression increment of $114.2 \mathrm{kPa}$ (level 2 to level $3)$, there was an average increase of 70 and $83 \%$ in $M_{\max }$ and $M_{\min (\theta M u)}$, respectively. The improvement of peak and post-peak capacity of masonry walls with the application of vertical pre-compression is a well-known phenomenon which has been observed and discussed in several past works (for example in Griffith et al. (2007)). Moreover, the increase of the maximum overturning moment is strongly affected by the static equilibrium due to the increase of stabilization forces.

\subsection{Energy dissipation capacity}

The capacity of the masonry elements to dissipate energy is one of their key structural properties, mainly when they are subjected to seismic load. Therefore, the hysteretic energy dissipation was evaluated for all tests considering the area of each load cycle and the results' evolution in terms of both cumulative dissipated energy and individual cycle energy are presented in Fig. 17a, b, respectively.

It was already noted that the hysteretic loops presented in Fig. 13 show that all specimens underwent plastic deformation and dissipated a significant amount of energy. Moreover, from the analysis of the cumulative dissipated energy results shown in Fig. 17a, it is clear that for the same rotation levels, the energy dissipation capacity of the walls increases with the pre-compression force. In general terms, the individual cycle energy curves presented in Fig. 17b stress the conclusions pointed out from the analysis of Figs. 13 and 17a underlining the more regular behaviour of the walls tested resorting to airbags in terms energy dissipation. Notwithstanding this fact, the walls tested with the point load setup clearly present more energy dissipation capacity (see Fig. 17a). 


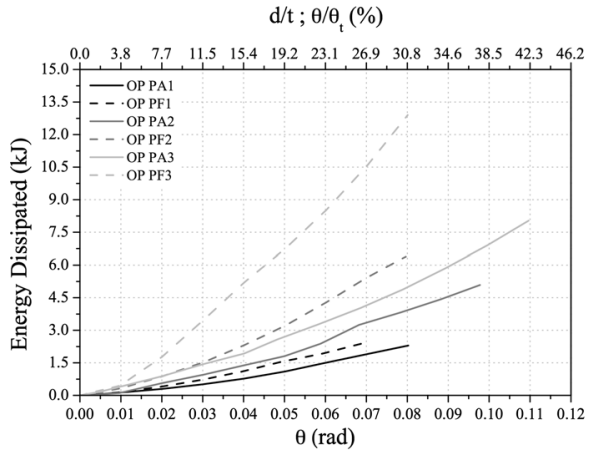

(a)

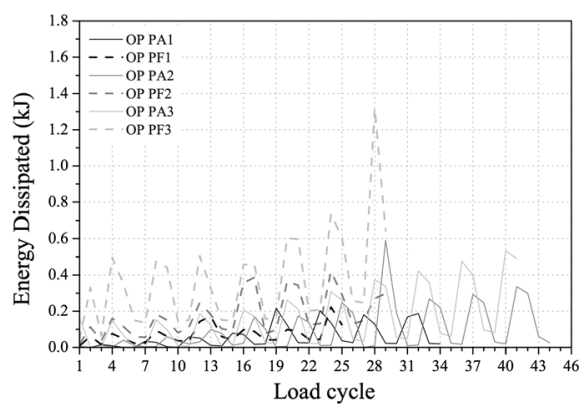

(b)

Fig. 17 Energy dissipation capacity: a cumulative dissipated energy; and $\mathbf{b}$ individual cycle energy

Figure 18 presents the sectional displacement curves built from the relative movements in the cross-sections, which were obtained on the basis of the displacement directions shown in Fig. 18a. As evidenced by these results, the behaviour of the walls tested with airbags is mainly in rocking, presenting a slight component of bending, while the walls tested with the line-load behaved in bending, also exhibiting some shear. These two distinct responses are demonstrated by the configuration of the displacement curves shown in Fig. 18 as well as by the cracking patterns observed at the end of the tests (see Fig. 21). Additionally, and as expected, the bending behaviour is more significant with the increase of the axial pre-compression state.

In order to characterize the hysteretic behaviour during the tests, Fig. 19 presents the evolution of the equivalent hysteretic damping computed by Eq. (5), which was initially presented by Shibata and Sozen (1976):

$$
\xi_{e q}(\%)=100 \cdot \frac{A_{h}}{2 \pi \cdot F_{m} \cdot d_{m}}
$$

where $A_{h}$ refers to the area inside one loop, while $F_{m}$ and $d_{m}$ are, respectively, the maximum force and maximum displacement achieved in the same loop.

The equivalent hysteretic damping evolution during the out-of-plane tests is interesting (Fig. 19a). Even though the results exhibit some trend, evidenced by the linear fitting included in Fig. 19b, the evolution of the equivalent hysteretic damping is quite irregular,

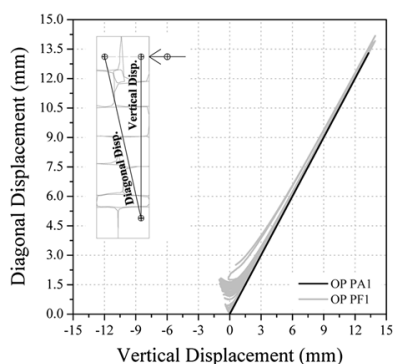

(a)

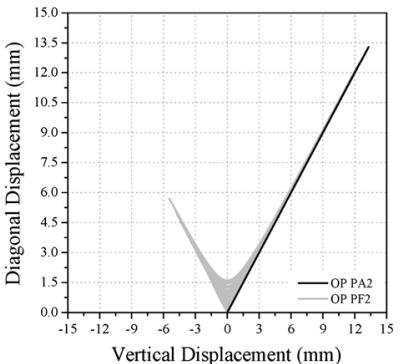

(b)

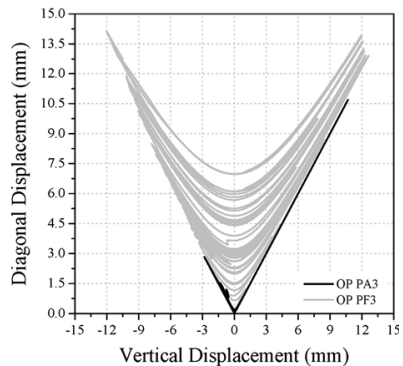

(c)

Fig. 18 Displacements on the transversal section of the walls: a OP PA1 versus OP PF1; b OP PA2 versus OP PF2; and c OP PA3 versus OP PF3 


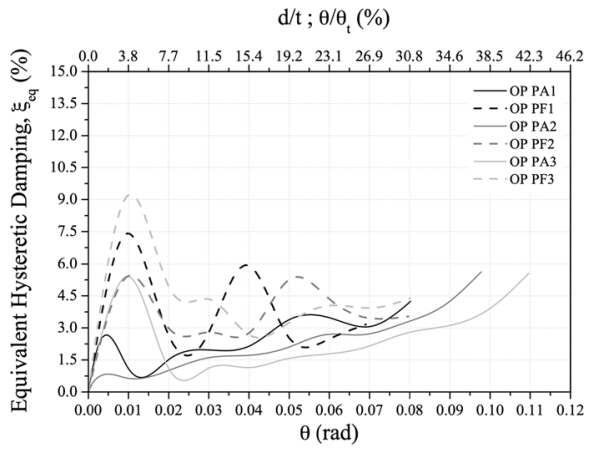

(a)

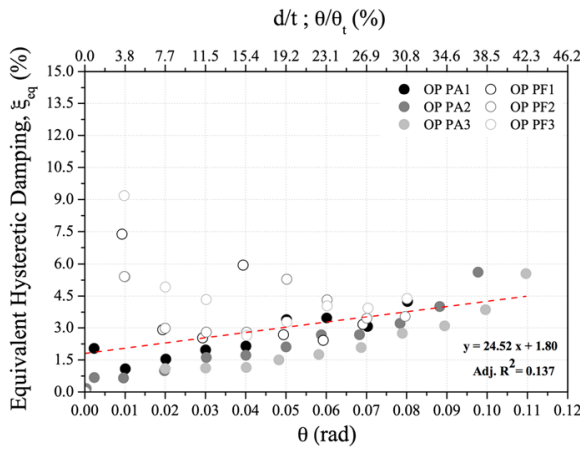

(b)

Fig. 19 Rotation versus equivalent hysteretic damping: a evolution during the tests; $\mathbf{b}$ linear fitting from the equivalent hysteretic damping results

particularly concerning the results obtained from the line-load tests. Considering average values, the equivalent hysteretic damping of the walls range between 2.2 and $4.6 \%$. This range, together with the shape of the curves presented in Fig. 19a, with no hysteretic damping plateau, suggests that the total capacity of these walls, in terms of energy dissipation capacity, might not have been experimentally reached.

\subsection{Analysis of frequencies decay during the tests}

On the basis of the study of frequency decay over the tests, some relevant conclusions about the progress of the out-of-plane tests over time are discussed, both in terms of the capacity of the masonry specimens and the damage level. As depicted in Fig. 20a, b which presents the frequencies measured during the airbag tests and the line-load tests respectively, the transversal frequencies' decay does not present a constant drop and well defined linear trend. However, it is worth noting that the changes of the decay slope of the curves are associated with the development of damage in the masonry specimens, which is responsible for the degradation of their global mechanical properties.

As summarized in Table 5, the difference between the frequencies measured before the tests and the frequencies found after the tests were on the average $-20.19 \%$ for the airbag tests and about $-23.96 \%$ for the line-load tests, which correspond to a decay of about -0.0033 and $-0.109 \mathrm{~Hz}$ per cycle, respectively.

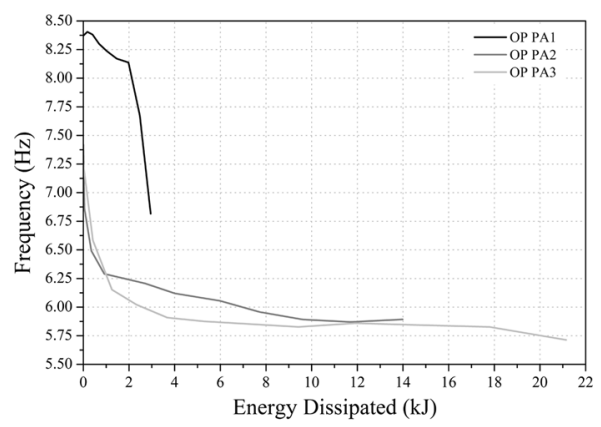

(a)

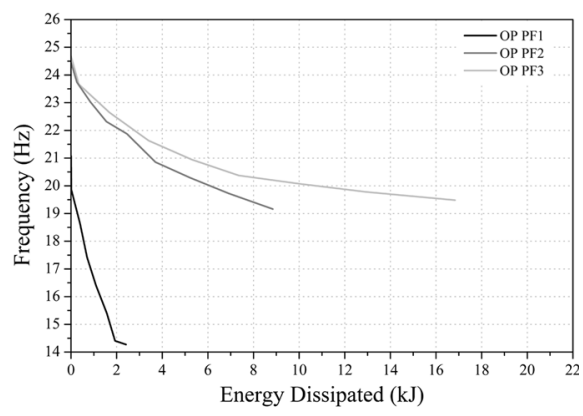

(b)

Fig. 20 Frequency decay over tests, in the out-of-plane direction. a Airbag tests, b Line-load tests 
Table 5 Frequency and Elastic Modulus decay over the out-of-plane tests

\begin{tabular}{|c|c|c|c|c|c|c|c|c|}
\hline \multirow[t]{3}{*}{ Test } & \multicolumn{4}{|c|}{ Fundamental frequency } & \multicolumn{4}{|c|}{ Elastic Modulus } \\
\hline & \multirow{2}{*}{$\begin{array}{l}F_{\text {initial }} \\
(\mathrm{Hz})\end{array}$} & \multirow[t]{2}{*}{$f_{\text {final }}(\mathrm{Hz})$} & \multicolumn{2}{|l|}{ drop } & \multirow{2}{*}{$\begin{array}{l}E_{\text {inicial }} \\
(\mathrm{GPa})\end{array}$} & \multirow{2}{*}{$\begin{array}{l}E_{\text {final }} \\
(\mathrm{GPa})\end{array}$} & \multicolumn{2}{|l|}{ drop } \\
\hline & & & $(\%)$ & (Hz/cycle) & & & $(\%)$ & (GPa/cycle) \\
\hline OP PA1 & 8.39 & 6.82 & -18.71 & -0.0449 & 0.53 & 0.35 & -33.96 & -0.0051 \\
\hline OP PA2 & 7.42 & 5.89 & -20.62 & -0.0333 & 0.42 & 0.27 & -35.71 & -0.0033 \\
\hline OP PA3 & 7.25 & 5.71 & -21.24 & -0.0335 & 0.40 & 0.25 & -37.50 & -0.0033 \\
\hline OP PF1 & 21.34 & 14.27 & -33.13 & -0.2828 & 0.44 & 0.20 & -54.55 & -0.0096 \\
\hline OP PF2 & 24.59 & 19.15 & -22.12 & -0.1876 & 0.58 & 0.35 & -39.66 & -0.0079 \\
\hline OP PF3 & 24.66 & 20.56 & -16.62 & -0.1414 & 0.59 & 0.41 & -30.51 & -0.0062 \\
\hline
\end{tabular}

Note that the proximity found between both of the results corroborate the fact that both of the experimental setups used in the tests herein presented are able to globally mobilize the out-of-plane response of this type of masonry elements, providing important information on their out-of-plane behaviour. Notwithstanding this fact, it is worth adding that from the analysis of the decay values it is also quite evident that the quantity of damage developed, per cycle, in the wall, expressed here in terms of Hz/cycle, is significantly higher in the walls tested with the line-load setup.

\subsection{Cracking patterns}

In general terms, the walls tested with airbags presented typical cracking patterns for a behaviour mainly governed by rocking, whereas the walls tested with line-load presented a cracking pattern more befitting with a response governed by bending (see Fig. 21).

Thus, over the course of the experiments, it was observed the opening of a single vertical crack along the interleaf bond up to a height defined by the dimension of the pivot stone block placed on the base section (in the case of the OP PA tests) and by the vertical height of the first header (in the case of the OP PF tests). As depicted in Fig. 22, such vertical crack is followed by the opening of a horizontal crack from which the relative interleaf displacement is more pronounced.
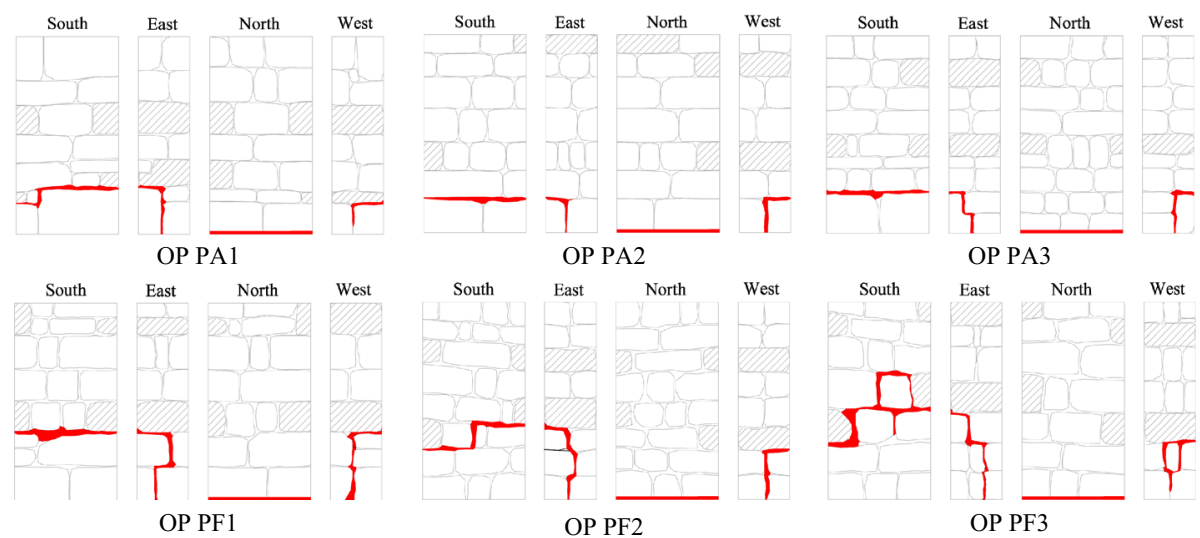

Fig. 21 Cracking patterns observed at the end of the out-of-plane tests 

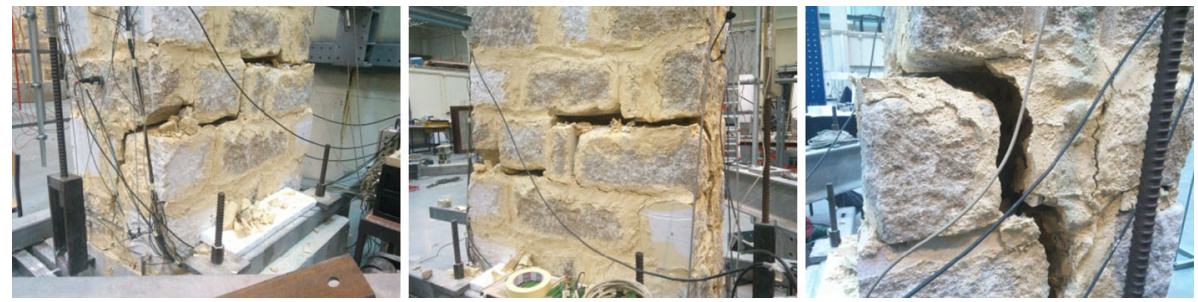

Fig. 22 Horizontal crack with relative interleaf displacement (from OP PF2)

It is important to highlight that no unit fail has occurred during the tests, with all failures occurring at the unit-mortar bonds (stepped cracking).

\section{Analytical study of the experimental results}

As stated by Tomaževič (1999), for analysis and design purposes the values of sectional forces, stresses and strains are usually determined based on the gross cross-sectional geometrical characteristics of the walls and assuming the elastic, homogeneous and isotropic global properties of masonry as structural material. According to this assumption, it is possible to carry out analytical-based assessments, which can provide valuable results for the development and calibration of new analytical approaches. Therefore, three different analysis are presented and discussed in this section:

1. The comparison between the elastic stiffness computed through Eq. (6) and both the initial and the effective stiffness obtained from the experiments;

2. The comparison between the static overturning moment obtained on the basis of a simplified static model and the maximum experimental overturning moment;

3. The analysis of the relation between the idealized ultimate displacement and the wall thickness.

Starting with the analysis of the ratios obtained from the experimentally-obtained values of stiffness, both the initial, $K_{i n i}$, and the effective stiffness, $K_{\text {eff }}$ (which the calculation was already discussed in Sect. 4.1) and the elastic stiffness of the walls, $K_{e l}$, evaluated resorting to Eq. (6):

$$
K_{e l}=\frac{3 E I}{h^{3}}
$$

where, $E$ is the Elastic Modulus, $I$, represents the moment of inertia of the wall's crosssection and $h$ is the total height of the wall. In this case, the Elastic Modulus value considered in this analysis was the mean value obtained from the vibration tests addressed in Sect. 2.3 (see Table 2). It is worth highlighting that the results obtained for ratio $K_{e l} / K_{\text {ini }}$ are quite interesting, presenting small variation ranges within each of the considered precompression levels. In fact, as shown in Table 6 , ratio $K_{e l} / K_{\text {ini }}$ was found to be in average $77 \%$ for the case of no pre-compression force, and 70 and $59 \%$ for a pre-compression force of 52 and $140 \mathrm{kN}$, respectively.

The analytical prediction herein performed is based on static equilibrium, considering rigid-body flexural/rocking behaviour. The simplified model withal the internal and external forces that compose the static system is presented in Fig. 23. 
Table 6 Comparison between the experimental results and the analytical predictions

\begin{tabular}{llllllllll}
\hline Test & $\begin{array}{l}K_{\text {ini }} \\
(\mathrm{kN} / \mathrm{m})\end{array}$ & $\begin{array}{l}K_{\text {eff }} \\
(\mathrm{kN} / \mathrm{m})\end{array}$ & $\begin{array}{l}K_{\text {eff }} / K_{\text {ini }} \\
(\%)\end{array}$ & $\begin{array}{l}K_{\text {el }} \\
(\mathrm{kN} / \mathrm{m})\end{array}$ & $\begin{array}{l}K_{\text {el }} / K_{\text {ini }} \\
(\%)\end{array}$ & $\begin{array}{l}K_{\text {eff }} / K_{\text {el }} \\
(\%)\end{array}$ & $\begin{array}{l}M_{\max } \\
(\mathrm{kNm})\end{array}$ & $\begin{array}{l}M_{O} \\
(\mathrm{kNm})\end{array}$ & $M_{\max } / M_{O}$ \\
\hline OP PA1 & 3707 & 1986 & 53.58 & 5426.6 & 75.51 & 70.95 & 14.57 & 14.64 & 1.00 \\
OP PF1 & 3575 & 1484 & 41.50 & & 78.29 & 53.02 & 15.28 & 15.19 & 1.01 \\
OP PA2 & 4137 & 2469 & 59.67 & & 67.66 & 88.21 & 28.30 & 32.84 & 0.86 \\
OP PF2 & 3893 & 1744 & 44.81 & & 71.90 & 62.31 & 33.08 & 33.39 & 0.99 \\
OP PA3 & 4712 & 2689 & 57.06 & & 59.50 & 96.07 & 47.33 & 61.44 & 0.77 \\
OP PF3 & 4769 & 2049 & 42.96 & & 58.69 & 73.20 & 57.02 & 61.99 & 0.92 \\
& Mean value & 49.93 & & 68.59 & 73.96 & & & 0.93 \\
& Coef. variation (\%) & 15.64 & & 11.92 & 21.60 & & & 10.30 \\
\hline
\end{tabular}

Fig. 23 Simplified analytical model used. a At $\Delta=0$, b At $\Delta=\Delta_{f}$ (incipient rocking)

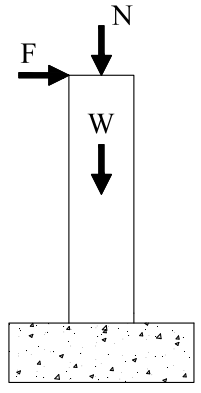

(a)

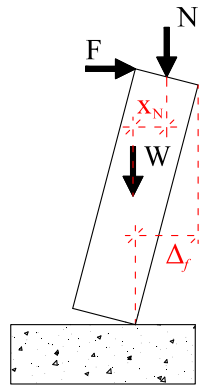

(b)

From such model it is then possible to compute the analytical static overturning moment of the wall, $M_{0}$, based on the limit equilibrium of the system, in Eq. (7) (Ferreira et al. 2015):

$$
M_{0}=\frac{W \cdot t}{2}+N\left(t-X_{N}\right)
$$

where $N$ represents the vertical pre-compression force acting on the top of the wall and $W$ and $t$ are respectively the total weight of the wall and its thickness. Finally, $X_{N}$ is the distance between the interior edge of the wall and the application point of the resultant of the vertical pre-compression force (Fig. 23).

The comparison between the maximum experimental overturning moment, $M_{\max }$, summarised in Table 4, and the corresponding analytical static overturning moment, $M_{O}$, considering the three levels of pre-compression forces used in the out-of-plane tests (i.e. $\mathrm{N}=0 \mathrm{kN}, \mathrm{N}=52 \mathrm{kN}$ and $\mathrm{N}=140 \mathrm{kN}$ ), is presented in Table 6 and graphically schematized in Fig. 24.

The maximum stability displacement, $\Delta_{f}$, is another interesting and useful parameter for describing the out-of-plane response of masonry walls. Although this value may be difficult to obtain directly from experimental tests, it is possible to idealise the final branch of the decay curve and accordingly, the maximum stability displacement based on the envelope curves presented in Fig. 25a. The slope of the decay branches was defined here by means of two experimentally-obtained points: the maximum experimental overturning 


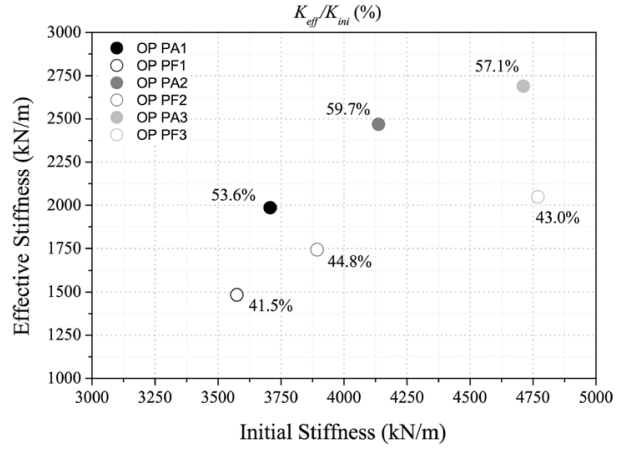

(a)

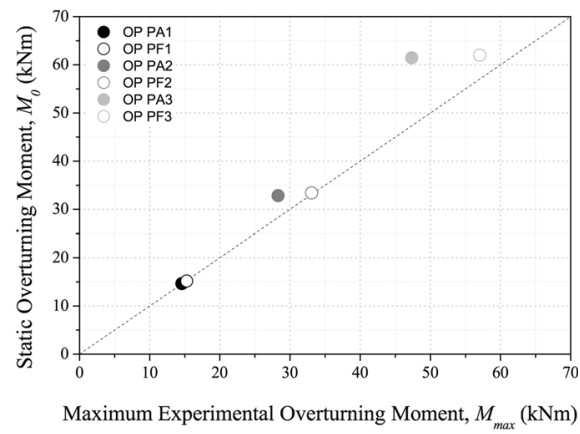

(b)

Fig. 24 Correlation between a initial and effective stiffness and b static and maximum experimental overturning moment

$\Delta / t$

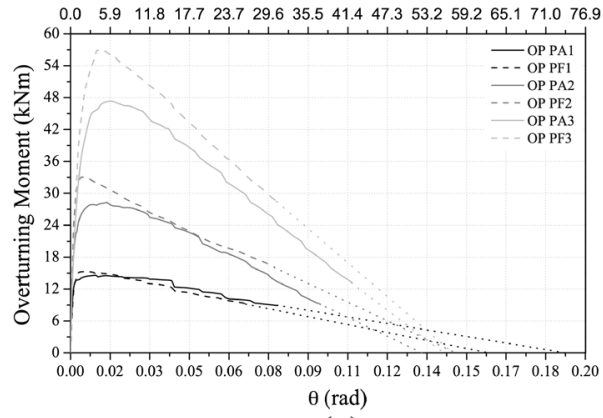

(a)
$\Delta / t$

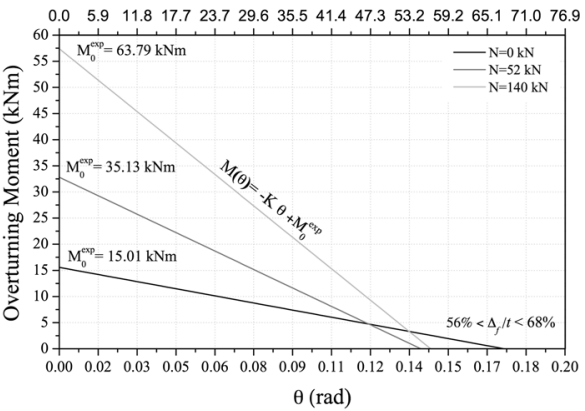

(b)

Fig. 25 Definition of the bilinear spines $M_{0}^{\exp }-\Delta_{f}$ : a idealization of the experimental decay branches; b bilinear spines obtained from the experimental results

moment, $M_{\max }$, and the overturning moment corresponding to the maximum experimentally imposed displacement, $M_{u}$. As can be observed in Fig. 25a and in Table 7, the experimental decay branches present a good agreement regarding the value of the maximum stability displacement, $\Delta_{f}$, resulting in a range of values from 0.53 to 0.74 . As also shown in Table 7 , the value of $\Delta_{f}$ tends to decrease as the vertical pre-compression force is increased. This fact, as well as the average value obtained for ratio $\Delta_{f} / t$, of about $60 \%$, are both in good agreement with previous proposals found in literature, wherein $\Delta_{f}$ is assumed as about $2 / 3$ of the wall thickness, $t$ (Griffith et al. 2003).

Figure $25 \mathrm{~b}$ depicts the idealised bilinear spines obtained for each pre-compression level, computed from the average of the slopes and overturning results summarized in Table 7.

Finally, one last note regarding the result of ratios $M_{0}^{\exp } / M_{0}$, presented in Table 7, which range between about 0.86 and 1.05 , with an average value of $0.99(7.14 \% \mathrm{CoV})$. 
Table 7 Definition of ratios $M_{0}^{\text {exp }} / M_{O}$ and $\Delta_{f} / \mathrm{t}$

\begin{tabular}{|c|c|c|c|c|c|c|c|}
\hline Test & $M(\theta)=-K \cdot \theta+M_{0}^{\exp }$ & $\begin{array}{l}M_{0}^{\exp } \\
(\mathrm{kNm})\end{array}$ & $\begin{array}{l}-\bar{K} \\
(\mathrm{kNm} / \mathrm{rad})\end{array}$ & $\begin{array}{l}\overline{M_{0}^{\exp }} \\
(\mathrm{kNm})\end{array}$ & $M_{0}^{e x p} / M_{O}$ & $\theta_{f}(\mathrm{rad})$ & $\Delta_{f} f t$ \\
\hline OP PA1 & $M(\theta)=79.94 \cdot \theta+15.36$ & 15.36 & 88.54 & 15.57 & 1.05 & 0.174 & 0.74 \\
\hline OP PF1 & $M(\theta)=97.14 \cdot \theta+15.78$ & 15.78 & & & 1.04 & 0.174 & 0.63 \\
\hline OP PA2 & $M(\theta)=231.24 \cdot \theta+31.56$ & 31.56 & 229.48 & 32.81 & 0.96 & 0.190 & 0.53 \\
\hline OP PF2 & $M(\theta)=227.71 \cdot \theta+34.06$ & 34.06 & & & 1.02 & 0.163 & 0.58 \\
\hline OP PA3 & $M(\theta)=366.24 \cdot \theta+53.08$ & 53.08 & 390.91 & 57.40 & 0.86 & 0.265 & 0.56 \\
\hline \multirow[t]{3}{*}{ OP PF3 } & $M(\theta)=415.56 \cdot \theta+61.72$ & 61.72 & & & 1.00 & 0.173 & 0.57 \\
\hline & & & \multicolumn{2}{|l|}{ Mean value } & 0.99 & & 0.60 \\
\hline & & & \multicolumn{2}{|c|}{ Coef. variation (\%) } & $7.14 \%$ & & 12.50 \\
\hline
\end{tabular}

\section{Final comments}

This paper reports an experimental campaign carried out at the LESE of FEUP, Porto, in order to study the out-of-plane behaviour of traditional stone masonry walls. Six full-scale stone masonry specimens were constructed by professional masons and tested resorting to two different loading techniques, under three distinct vertical pre-compression states. Three of the specimens were subjected to an out-of-plane surface load resorting a system of airbags and the remaining were tested by means of an out-of-plane horizontal line-load. Before testing, a thorough characterisation of the masonry specimens was performed, namely concerning their most important mechanic, geometric and dynamic features. Subsequently, the principal results obtained from the six out-of-plane tests performed were compared and discussed, and the paper is closed with an analytical study, carried out on the basis of such experimental results, wherein a comparison between analytical and experimental stiffness, strength and displacement results is presented.

Among other relevant conclusions that were pointed out herein, this experimental campaign allowed to observe that both the test setups (line load and airbags) were able to globally mobilise the out-of-plane response of all the masonry walls. In general terms, it is possible to state that the walls presented large displacement capacity, with ultimate displacement over wall thickness ratios in the range between 26 and $42 \%$. Moreover, substantial energy dissipation capacity was also observed. As expected, the capacity of the walls to dissipate energy was proved to be highly influenced by boundary conditions, namely by their vertical pre-compression state. Last but not least, very interesting results were obtained from the simple analytical model used for the identification of some experimental-based ratios. Among the discussed, the result obtained for ratio $\Delta_{f} / t$, of about $60 \%(12.50 \% \mathrm{CoV})$, is one of the most relevant findings, showing a good agreement with some previous studies presented in literature (see for example Griffith et al. 2003). Finally, it is important to note that, as also reported in Griffith et al. (2003), this ratio is also very influenced by the vertical pre-compression state of the masonry walls.

Acknowledgments The authors would like to acknowledge the technicians of the Laboratory of Earthquake and Structural Engineering (LESE), Mr. Valdemar Luis and Mr. André Martins, for their support in the experimental activity reported in this paper and to thank the unknown reviewers for their constructive and helpful remarks. This experimental campaign was conducted with financial contribution of the Portuguese Foundation for Science and Technology (FCT) through the national research project "Field Experimental Characterization of Stone Masonry Construction under Earthquake Actions" (PTDC/ECM/ 104520/2008). 
Conflict of Interest The authors declare that they have no conflict of interest.

\section{References}

Almeida C (2013) Paredes de alvenaria do Porto: Tipificação e caracterização experimental. Ph.D. thesis, Faculty of Engineering of the University of Porto, Portugal

Almeida C, Guedes JP, Arêde A et al (2012) Physical characterization and compression tests of one leaf stone masonry walls. Constr Build Mater 30:188-197. doi:10.1016/j.conbuildmat.2011.11.043

ASTM C 496-71 (2001) Standard test method for splitting tensile strength of intact rock core specimens. American Society for Testing and Materials, West Conshohoken

Augenti N, Parisi F (2010) Learning from construction failures due to the 2009 L'Aquila, Italy, earthquake. J Perform Constr Facil 24:536-555. doi:10.1061/(ASCE)CF.1943-5509.0000122

Augenti N, Parisi F, Acconcia E (2012) MADA: online experimental database for mechanical modelling of existing masonry assemblages. In: Proceedings of the 15th world conference on earthquake engineering, Lisbon, Portugal, 24-28 September 2012

Bayraktar A, CoŞkun N, Yalçin A (2007a) Damages of masonry buildings during the July 2, 2004 Doğubayazıt (Ağri) earthquake in Turkey. Eng Fail Anal 14:147-157. doi:10.1016/j.engfailanal.2005. 11.011

Bayraktar A, Coşkun N, Yalçin A (2007b) Performance of masonry stone buildings during the March 25 and 28, 2004 Asskale (Erzurum) earthquakes in Turkey. J Perform Constr Facil 21:432-440. doi:10.1061/ (ASCE)0887-3828(2007)21:6(432)

Clough RW, Penzien J (1975) Dynamics of structures. McGraw-Hil, New York

Consiglio Superiore dei lavori Pubblici (2009) Instructions 2009. Circolare esplicativa, n. 617 (in Italian)

Costa AA (2012) Seismic assessment of the out-of-plane performance of traditional stone masonry walls. $\mathrm{Ph} . \mathrm{D}$. thesis, Faculty of Engineering of the University of Porto, Portugal

Costa A, Costa AA, Arêde A, et al. (2012a) Out-of-plane in situ cyclic testing of unreinforced stone masonry walls with distributed loads. 15th IB2MaC, International Brick and Block Masonry Conference, Florianópolis, Brazil, 3-6 June 2012

Costa AA, Arêde A, Costa A, Oliveira CS (2012b) Out-of-plane behaviour of existing stone masonry buildings: experimental evaluation. Bull Earthq Eng 10:93-111. doi:10.1007/s10518-011-9332-9

Costa AA, Arêde A, Campos Costa A et al (2013a) Out-of-plane behaviour of a full scale stone masonry façade. Part 1: specimen and ground motion selection. Earthq Eng Struct Dyn 42:2081-2095. doi:10. 1002/eqe. 2313

Costa AA, Arêde A, Campos Costa A et al (2013b) Out-of-plane behaviour of a full scale stone masonry façade. Part 2: shaking table tests. Earthq Eng Struct Dyn 42:2097-2111. doi:10.1002/eqe.2314

Costa AA, Arêde A, Penna A, Costa A (2013c) Free rocking response of a regular stone masonry wall with equivalent block approach: experimental and analytical evaluation. Earthq Eng Struct Dyn 42:2297-2319. doi:10.1002/eqe.2327

D'Ayala D, Paganoni S (2011) Assessment and analysis of damage in L'Aquila historic city centre after 6th April 2009. Bull Earthq Eng 9:81-104

D’Ayala D, Shi Y (2011) Modeling masonry historic buildings by multi-body dynamics. Int J Archit Herit 5:483-512

D'Ayala D, Speranza E (2003) Definition of collapse mechanisms and seismic vulnerability of historic masonry buildings. Earthq Spectra 19:479-509

De Felice G (2011) Out-of-plane seismic capacity of masonry depending on wall section morphology. Int J Archit Herit 5:466-482. doi:10.1080/15583058.2010.530339

Decanini L, De Sortis A, Goretti A et al (2004) Performance of masonry buildings during the 2002 Molise, Italy, earthquake. Earthq Spectra 20:S191

EN 1015-11 (1999) Methods of test for mortar for masonry-Part 11: determination of flexural and compressive strength of hardened mortar. Eur Comm Stand, Bruxelles

EN 14580 (2005) Natural stone test methods. Determination of static elastic modulus. Eur Comm Stand, Bruxelles

EN 1926 (2006) Natural stone test methods. Determination of uniaxial compressive strength. Eur Comm Stand, Bruxelles

Ferreira TM (2015) Out-of-plane seismic performance of stone masonry walls: experimental and analytical assessment. Ph.D. thesis, University of Aveiro, Portugal 
Ferreira T, Vicente R, Varum H et al (2012) Out-of-plane seismic response of stone masonry walls: an analytical study of a real pier. 15th World conference on earthquake engineering, Lisbon, Portugal, 4-28 Sept 2012

Ferreira TM, Costa AA, Costa A (2014) Analysis of the out-of-plane seismic behaviour of unreinforced masonry: a literature review. Int J Archit Herit. doi:10.1080/15583058.2014.885996

Ferreira TM, Costa AA, Vicente R, Varum H (2015) A simplified four-branch model for the analytical study of the out-of-plane performance of regular stone URM walls. Eng Struct 83:140-153. doi:10.1016/j. engstruct.2014.10.048

Giuffrè A (1990) Letture sulla meccanica delle murature storiche. Kappa, Rome (in Italian)

Giuffrè A (1996) A mechanical model for statics and dynamics of historical masonry buildings. In: Petrini V, Save M (eds) Protection of the architectural heritage against earthquakes, CISM courses and lectures no 359. Springer, Udine, pp 71-152

Gomes A, Arêde A, Ferreira TM, Costa AA (2013) An empirical correction factor for the rectification of experimental out-of-plane tests results with airbag testing. LESE Report, Laboratory of Earthquake and Structural Engineering, Faculty of Engineering, University of Porto, Portugal

Griffith MC, Magenes G, Melis G, Picchi L (2003) Evaluation of out-of-plane stability of unreinforced masonry walls subjected to seismic excitation. J Earthq Eng 7:141-169. doi:10.1080/13632460309350476

Griffith MC, Vaculik J, Lam NTK et al (2007) Cyclic testing of unreinforced masonry walls in two-way bending. Earthq Eng Struct Dyn 36:801-821. doi:10.1002/eqe.654

Luigli G (1957) La tecnica edilizia romana. Bardi, Rome (in Italian)

Magalhães A, Veiga MR (2009) Physical and mechanical characterisation of ancient mortars. Application to the evaluation of the state of conservation. Mater Constr 59:61-77. doi:10.3989/mc

Maqsood ST, Schwarz J (2010) Building vulnerability and damage during the 2008 Baluchistan earthquake in Pakistan and past experiences. Seismol Res Lett 81:514-525. doi:10.1785/gssrl.81.3.514

National Instruments (2010) LabView SignalExpress

Restrepo-Vélez LF, Magenes G, Griffith MC (2014) Dry stone masonry walls in bending-Part I: static tests. Int J Archit Herit 8:1-28. doi:10.1080/15583058.2012.663059

Romão X, Costa AA, Paupério E et al (2013) Field observations and interpretation of the structural performance of constructions after the 11 May 2011 Lorca earthquake. Eng Fail Anal 34:670-692. doi:10. 1016/j.engfailanal.2013.01.040

Sayin E, Yön B, Calayır Y, Gör M (2014) Construction failures of masonry and adobe buildings during the 2011 Van earthquakes in Turkey. Struct Eng Mech 51:503-518. doi:10.12989/sem.2014.51.3.503

Sayın E, Yön B, Calayır Y, Karaton M (2013) Failures of masonry and adobe buildings during the June 23, 2011 Maden-(Elazığ) earthquake in Turkey. Eng Fail Anal 34:779-791. doi:10.1016/j.engfailanal. 2012.10.016

Shibata A, Sozen MA (1976) Substitute-structure method for seismic design in R/C. J Struct Div (ASCE) 102:1-18

Structural Vibration Solution (2012) ARTeMIS Extractor Pro. Release 5.3

Swain GF (1927) Structural engineering: stresses, graphical statics and masonry. McGraw-Hill Company Inc., New York

Tomaževič M (1999) Earthquake-resistant design of masonry buildings. Series on innovation in structures and construction, vol 1. Imperial College Press, London

Trovalusci P, Baggio C (2003) An optimisation algorithm for the collapse detection of stone masonry structures. In: Brebbia CA (ed) STREMAH structural studies, repair and maintance of heritage architecture VIII. WIT Press, Ashurst, pp 473-481

Vaculik J, Griffith MC, Magenes G (2014) Dry stone masonry walls in bending-part II: analysis. Int J Archit Herit 8:1-28. doi:10.1080/15583058.2012.663059

Vasconcelos G (2005) Experimental investigations on the mechanics of stone masonry: characterization of granites and behavior of ancient masonry shear walls. PhD thesis, University of Minho, Portugal 